\title{
COMBINING GUM AND CONTRACEPTIVE SERVICES FOR YOUNG PEOPLE: PROFILE OF AN INNOVATIVE CLINIC
}

\author{
Sue Bloxham, Senior Lecturer, Applied Social Sciences, St Martins College; \\ Sue Capstick, Sexual Health Specialist Nurse, Ryelands House; \\ Anne Greenwood, General Practitioner, Strawberry Gardens Surgery, Heysham
}

\section{INTRODUCTION}

The nineties has witnessed a growth in specialist family planning provision for adolescents including advisory clinics for young people. However, there has been no parallel development of teenager-friendly genito-urinary medicine (GUM) services, despite the prevalence of sexually transmitted diseases (STDs) in the adolescent age group. This article profiles a young persons' clinic in Morecambe which operates a combined family planning/GUM clinic one afternoon a week in a multi-agency, shop front, youth project. Attendances are high, particularly amongst young teenagers and males. The clinic enjoys a $66 \%$ follow-up rate and $11 \%$ of clients have crossed over from one service to the other on succeeding visits. Seventeen cases of chlamydia were diagnosed in nine females under 18. The benefits of a 'one stop' clinic and the youth project location are discussed.

The last decade has witnessed a growing interest in the effective provision of sexual health services for young people. Services for young people ${ }^{(1,2)}$, including specialist youth clinics $^{(3)}$ and broader-based advisory projects run by youth and voluntary organisations ${ }^{(2)}$, have been introduced. Consequently, young people's clinics are now becoming more widespread in the UK and reported results indicate that they are well used and popular with young people $\mathrm{e}^{(4.5,6,7)}$, and increase access to contraception ${ }^{(8,9,10)}$. It has, however, proved difficult to provide outcome measures associated with lowered rates of teenage pregnancy ${ }^{(5,11)}$, except by extrapolation from research on contraceptive services in general ${ }^{(12)}$. Nevertheless, preventing teenage pregnancies may be particularly cost-effective given the likely social costs of such pregnancies ${ }^{(12)}$.

Sexual health provision for young people has been largely concerned with preventing unwanted pregnancies and providing appropriate contraception with "little, if any, evidence of an expressed need (by staff) to reduce sexually transmitted diseases in young people"(1). Only $18 \%$ of health authority specialist services for young people offer screening for STDs ${ }^{(13)}$, although young people are a high risk population ${ }^{(13)}$. For example, $10 \%$ of sexually active young women are infected with chlamydia ${ }^{(7)}$, yet a recent survey indicated that only $4 \%$ of GUM clinics hold sessions designated especially for them ${ }^{(13)}$

Dedicated GUM provision for young people may not be the best solution. Although family planning and genitourinary services in the UK are traditionally provided separately, there is some evidence that clients, at least, would prefer one stop access ${ }^{(14.15)}$, and providing GUM and family planning 'under one roof'(16) would be an improvement.
Young people's ignorance of STDs ${ }^{(7)}$ and poor record in following up referrals ${ }^{(4)}$ suggest that providing GUM services within contraceptive clinics may improve their access to GUM, and, not surprisingly, clients would prefer GUM to be provided within family planning services rather than viceversa $^{(15)}$.

In addition, there has been a growing general emphasis on the benefits of multi-agency working ${ }^{(17)}$ and this is considered particularly appropriate in the field of teenage sexual health where links between health services, voluntary organisations and youth services have been particularly stressed ${ }^{(18,2)}$. Research suggests that sexual health is a highly appropriate field for inter-agency collaboration because of the distinctive range of skills, roles, relationships ${ }^{(18)}$ and access ${ }^{(7)}$ to young people offered by different professional traditions.

\section{THE CLINIC}

The Young Persons' Clinic (known as YPC) was set up in Morecambe in 1994 and the service is provided by Lancaster Priority Services NHS Trust. Central Morecambe is an area of social deprivation with high levels of unemployment, low skill levels and large numbers of transient young people in multiple occupancy accommodation ${ }^{(20)}$.

YPC operates for one two-hour session per week timed to fit in with the after-school movement of young people (4.00$6.00 \mathrm{pm}$ ), and was initially established in the local health centre. Staff were unhappy with the clinical nature of the surroundings and wished to increase the existing links with other services for young people. Therefore the clinic was moved in May 1997 to the Young People's Information Shop based in a town centre building which houses a range of voluntary and statutory welfare services for young people. The clinic is staffed by one doctor with clinical experience in family planning and GUM, three family planning nurses, a receptionist and a youth worker, all of whom are female. One family planning nurse currently works in a main GUM clinic as a health adviser and is responsible for contact tracing. The clinic is publicised through other professionals, particularly school nurses, and via publicity materials including creditcard sized information cards (see Figure 1).

The YPC was set up to offer both GUM and family planning services for the reasons discussed above. In addition, a combined approach was considered to encourage a more holistic view of sexual health amongst staff and clients. A combined clinic was also felt to be more convenient for clients and a cost-effective option. 

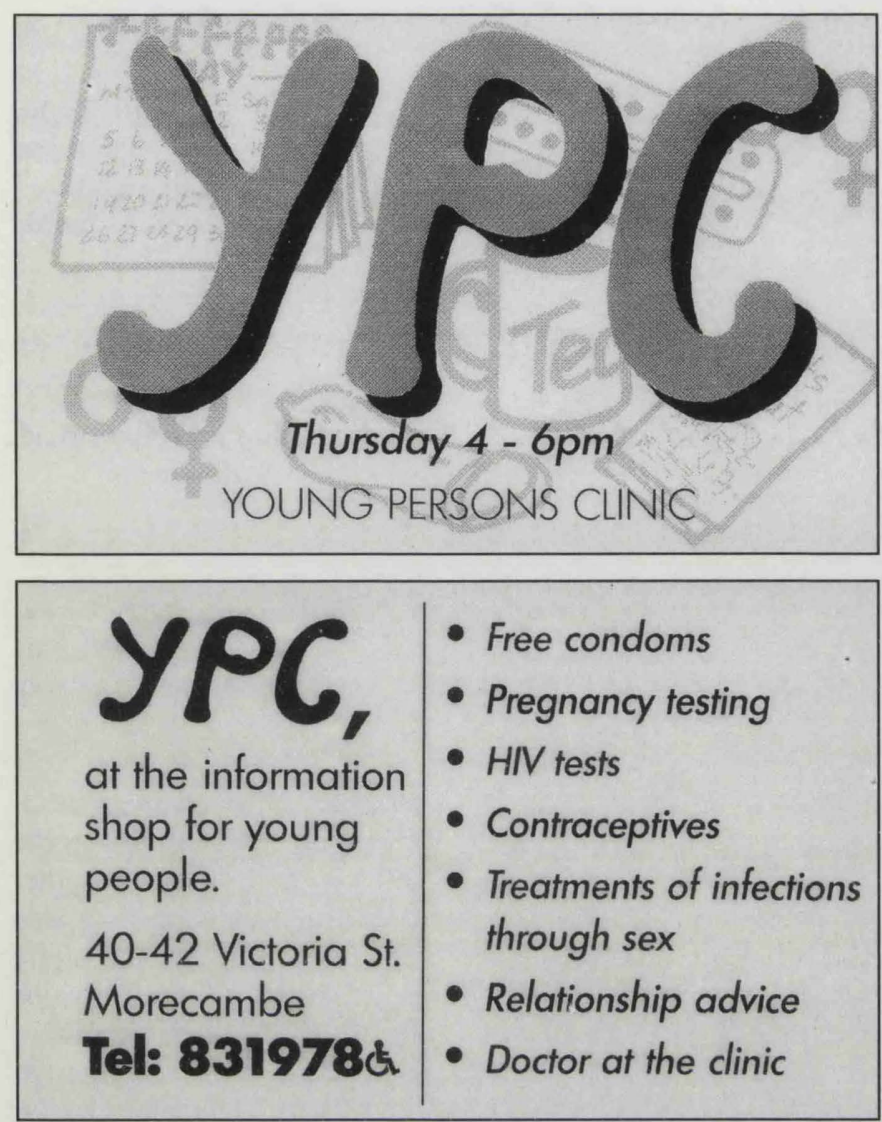

Figure 1 The information card (front and back) used to publicise the YPC

The YPC aims to provide a confidential service to all young people, a safe environment in which to talk about sexual health and related concerns, accurate information, and non-judgemental advice and help on all aspects of sexual health and related issues such as drugs and relationships. The service includes free pregnancy testing, contraceptives and treatment for STDs. Within this non-judgemental framework, staff do encourage clients to think about the consequences of their behaviour.

Nurse protocols have been devised for administering emergency contraception and re-issuing the pill and Depo Provera. The purpose of the protocols is to improve the efficiency of the clinic staff by providing an enhanced role for the nurse and thus reducing pressure on the doctor with a resulting reduction in client waiting time. Other reports have identified short waiting times as important for youth clinics(7), if only to reduce the potential of rowdiness amongst those having to wait too long ${ }^{(5,6)}$. On arrival, clients are shown a list of services written in simple language such as 'condoms', 'emergency contraception', 'pregnancy test', 'sexual infection', and 'not sure' and asked to point at which one they want. A youth worker is available in the reception area to chat to those waiting and to provide a link to the other youth services available in the building. Referrals are made from the clinic to other agencies in the building for issues such as housing or benefit problems, and the other services refer young people to the clinic when appropriate.

\section{REVIEW PERIOD AND DATA}

Data for this profile was collected from a review of attendances over a period of one year from October 1996 to September 1997, including information about the sex of the client, whether it was a first or follow-up visit, their age, whether GUM or family planning services were used, any GUM tests that were conducted and any GUM diagnosis. For
November 1997 to January 1998, data was also collected from 40 clients on where they had heard about the clinic. The data was compared with young people's attendances at the local family planning clinic in the year prior to the establishment of YPC.

\section{CLINIC ATTENDANCE}

879 visits (average of 17.2 per session) were made to the clinic during the year involving 382 different clients. Of these clients, $23 \%$ were male and $77 \%$ were female with slightly over a third under 16 years of age and two thirds under 18 . Figure 2 shows the breakdown of sex and age group. Although there were only three 12 -year-olds, the figures for 13-, 14- and 15-year-olds are 18, 35 and 78 respectively. Fifteen-year-olds are the largest group to use the clinic, followed by 16 -year-olds ( 70 clients). When all client visits are taken into account, the peak age is 16 with $55 \%$ of all visits being from 15-, 16- and 17-year-olds. These figures compare well with the Brook Advisory Centres in relation to attracting younger teenagers (13\% under 16 and $21 \%$ 16- and 17 -year-olds at Brook) and males (11\% at Brook) although their centres show general trends in this direction ${ }^{(7)}$.

\begin{tabular}{|l|c|c|c|c|c|}
\hline & under 16 & $16 \& 17$ & $18 \& 19$ & 20 \& over & $\begin{array}{c}\text { age } \\
\text { unknown }\end{array}$ \\
\hline $\begin{array}{l}\text { Male } \\
n=88\end{array}$ & $30(34)$ & $15(17)$ & $14(15.9)$ & $23(26.1)$ & $6(6.8)$ \\
\hline $\begin{array}{l}\text { female } \\
n=294\end{array}$ & $105(35.7)$ & $104(35.3)$ & $34(11.5)$ & $49(16.6)$ & $2(.7)$ \\
\hline $\begin{array}{l}\text { total } \\
n=382\end{array}$ & $135(35.3)$ & $119(31.2)$ & $48(12.6)$ & $72(18.8)$ & $8(2.1)$ \\
\hline
\end{tabular}

Figure 2 Age and sex distribution of all clients (percentages in brackets)

The data shows that $62.5 \%$ of clients (25) claimed to have heard about the clinic through friends, with $15 \%$ (6) mentioning school or school nurses as their contact point. Several other sources were also identified by very small numbers including advertising, other health services and the telephone helpline.

The clinic enjoys a good rate of return attendances with $66.1 \%$ of clients making at least one follow-up visit (discounting new patients in the last four weeks of the research period). A review of those who did not make a return visit found that they were likely to be older than average and to have received family planning rather than GUM services.

$75.7 \%$ of first visits are recorded as involving family planning services but this reduces to $69.3 \%$ for all visits, which is largely explained by the greater number of followup visits for GUM treatment, such as treatment of genital warts. Overall visits show that family planning is the element of the service more likely to be used by clients under 18 with $80.9 \%$ of family planning visits being taken by under- $18 \mathrm{~s}$ compared with $33.4 \%$ of GUM visits.

\begin{tabular}{|l|rc|cc|}
\hline & \multicolumn{2}{|c|}{ Under 18 years } & \multicolumn{2}{c|}{18 to 25 years } \\
YPC & $\begin{array}{c}\text { Morecambe } \\
\text { FPC }\end{array}$ & YPC & $\begin{array}{c}\text { Morecambe } \\
\text { FPC }\end{array}$ \\
\hline males & 45 & 5 & 37 & 5 \\
\hline females & 209 & 160 & 80 & 113 \\
\hline
\end{tabular}

Figure 3 Comparison of YPC clients with Morecambe Family Planning Clinic, 1993-94 
A comparison of these results with previous use by young people of the Morecambe Family Planning clinic (see Figure 3) suggests that the YPC is attracting client groups, particularly males, who may not have used FP services in the past.

\section{GUM SERVICES}

$20.7 \%$ of first visits during the research period were recorded as resulting in GUM services, although the proportion of all visits which involved GUM advice, screening or treatment increases to $28.1 \%$. Figures 4 and 5 show the number of screening tests that were carried out and diagnoses made by age group.

\begin{tabular}{|l|c|c|}
\hline & females & males \\
\hline High vaginal swab & 66 & - \\
\hline Gonorrhoea & 71 & 24 \\
\hline Chlamydia & 71 & 24 \\
\hline HIV & 13 & 7 \\
\hline Hepatitis B & 13 & 7 \\
\hline Hepatitis C & 2 & 0 \\
\hline Syphilis & 13 & 7 \\
\hline
\end{tabular}

Figure 4 Samples taken or conditions sought

\begin{tabular}{|l|c|c|c|c|}
\hline & $\begin{array}{c}\text { under 16 } \\
\text { years old }\end{array}$ & $\begin{array}{c}16 \text { \& 17 } \\
\text { years old }\end{array}$ & $\begin{array}{c}18 \text { years } \\
\text { and over }\end{array}$ & $\begin{array}{c}\text { age } \\
\text { unknown }\end{array}$ \\
\hline Thrush & 1 & 1 & 4 & 0 \\
\hline Scabies & 0 & 2 & 1 & 0 \\
\hline Pubic Lice & 0 & 0 & 3 & 0 \\
\hline NSU & 0 & 0 & 2 & 0 \\
\hline Gonorrhoea & 0 & 1 & 3 & 0 \\
\hline Warts & 1 & 5 & 11 & 0 \\
\hline Chlamydia & 4 & 5 & 7 & 1 \\
\hline Herpes & 0 & 0 & 3 & 0 \\
\hline Gardnerella & 1 & 2 & 1 & 0 \\
\hline
\end{tabular}

Figure 5 GUM diagnoses by age

Whilst the diagnoses for STDs tend to be concentrated amongst the older clients, the incidence of nine cases of chlamydia in the under-18s, all of whom were female, suggests the value of such a combined clinic. The clinic uses sensitive inquiry of personal medical history and other indicative factors to decide whether STD screening should be suggested to clients attending for family planning. Five of the females with a positive diagnosis for chlamydia were crossover clients whose previous visit was for family planning services.

Overall there were 41 crossovers between services for individual clients: 25 clients who received family planning services on their first visit during the research period, were provided with GUM services on one or more subsequent visits. Likewise 16 clients crossed over from GUM to family planning services. This evidence also tends to support the principle that combined sexual health services for young people may be more successful at targeting clients who are not aware that they need the other service, particularly GUM.

\section{DISCUSSION}

The clinic has been successful in achieving high attendance levels particularly amongst young teenagers and males and reflects the patterns of attendance in other specialist clinics ${ }^{(5)}$. Criteria identified $^{(2)}$ as essential for young people's family planning services include:

\section{- no appointment necessary}

- convenient opening times and location

- provision of advice on any health problem or ability to act as a link to other services to meet other health needs

\section{- free pregnancy tests}

- women staff available, including doctors

- confidentiality

clients can attend with friends

- telephone advice/help available

In all cases the YPC fulfils the criteria, exceeding it in the case of providing wider health services and referral to other agencies. The location in a youth information shop may also make it more comfortable for young people to use the clinic because the sexual health nature of their visit is not obvious to observers. Outreach work in local schools through school nurses and youth workers is also considered vital to high attendances, although the data shows that 'friends' are by far the chief source of referral.

The higher attendances at YPC may, however, be a feature of the national increase in young women attending family planning clinics ${ }^{(21)}$. There has been a threefold increase in under-16 attendances in the six years from 1989 to $1995^{(21)}$

A key factor in explaining the change is probably the growth of both provision and promotion of specialist services for young people ${ }^{(2)}$. In other words, the YPC may be a good example of the national trend in a local context.

YPC staff also believe that the clinic has succeeded in targeting vulnerable young people such as those with poor educational achievement, drug users and those with little family support. In their view, this has been achieved through their location in a multi-agency youth project with close links to other services for young people. In addition, it may be a feature of staff competency. Staff need not only to be competent as nurses or doctors, but also to have good skills in working and building relationships with young people. Adequate time for consultations is also important. The young age and low ability of some make the consultations heavy on time and very demanding in their intensity. Other research has indicated the importance to young people of not feeling rushed by clinic staff ${ }^{(18)}$. The high rate of follow-up visits and the high referral through 'friends' supports the view that most young clients feel comfortable using YPC.

The major innovative achievement of YPC appears to be the diagnosis of STD infections in clients who would not have used a GUM facility because they were embarrassed, did not know where to go or were not aware of any symptoms. Only $23 \%$ of the 16-24 age group have heard of chlamydia ${ }^{(7)}$. Therefore it is likely that whilst most young people may be aware that sexual activity can lead to pregnancy, few will be aware of the risk of contracting chlamydia without professional intervention to alert them to the risk. The staff at YPC consider that their success in diagnosing such infections has been accomplished because of 
the combined 'one stop' service that is offered. Once a young person has visited the clinic, they know what and who to expect. Consequently, the experience of YPC strongly supports further development of youth centre-based, combined services for young people as an accessible and cost effective way of promoting young people's sexual health.

\section{Acknowledgement}

We should like to acknowledge the work of Judy Park, former clinical nurse specialist in family planning at YPC, who was a driving force behind the clinic opening.

\section{REFERENCES}

1 Pitts M, Burtney E, Dobraszczy C 'There is no shame in it any more': how providers of sexual health advice view young people's sexuality Health Edu Res 1996; 11(1):1-9

2 Peckham S, Ingham R, Diamond I Teenage Pregnancy: Prevention and programmes University of Southampton: Institute of Health Policy Studies

3 Royal College of Obstetricians and Gynaecologists Report of the RCOG Working Party on Unplanned pregnancy London: RCOG 1991

4 Smart S Addressing the health needs of teenagers with a drop-in clinic Nursing Standard 1996; 10(43):43-45

5 Williams EC, Kirkman RJE, Elstein Profile of young peoples' advice clinic in reproductive health, 1988-93 $\mathrm{Br}$ Med J 1994; 309:786-8

6 Public Health Resource Centre The Young people's Health Centre and Peer education project, Denton, Tameside PHRC 1995

7 Brook Advisory Centres Annual Report 1996/1997 London: BAC 1997

8 Kirby D, Waszak C, Zeigler J Six school-based clinics: their reproductive health services and impact on sexual behaviour Fam Plann Perspect 1994; 23(1):6-16

9 Dryfoos JG Full Service Schools San Francisco: JosseyBass 1994
10 NHS Centre for Reviews and Dissemination Preventing and reducing the adverse effects of unintended teenage pregnancies Effective Health Care 1997; 3(10):1-11

11 Kirby D et al The effects of school-based health clinics in St Paul on school-wide birthrates Fam Plann Perspect 1993; 25(12):2-16

12 McGuire, Hughes D The Economic of Family Planning Services FPA London. 1995

13 The British Cooperative Clinical Group. Provision for sexual health care of adolescents in genitourinary medicine clinics in the United Kingdom Genitourin Med 1997; 73:453456

14 Walsh J Family planning provision in genitourinary medicine: a quiet revolution. Br J Fam Plan 1996: 22:27-30

15 Jones M Clients express preference for one stop sexual health shop. Nursing Times 1996; 96(21):32-33

16 Stedman Y, Elstein M Rethinking Sexual Health Clinics Br Med J 1995; 310):342-343

17 Leathard A Inter-professional developments in Britain: an overview in Leathard, A (ed) Going interprofessional: working together for health and welfare London: Routledge, 1994

18 Allen I Family Planning and Pregnancy Counselling Projects for Young People London: Policy Studies Institute. 1991

19 Bloxham S A case-study of inter-agency collaboration in the education and promotion of young people's sexual health. Health Ed J 1996; 55:389-403

20 Lancaster and Morecambe College Morecambe SRB Project: Labour Market Survey. Lancaster: unpublished. 1996

21 Department of Health Health and personal social service statistics for England London: HMSO 1996 